\title{
Finite element analysis of TMT vibrations transmitted through Telescope-Enclosure-Soil Interaction
}

Genady Shagal, Doug G. MacMynowski, Konstantinos Vogiatzis

Genady Shagal, Doug G. MacMynowski, Konstantinos Vogiatzis, "Finite element analysis of TMT vibrations transmitted through Telescope-EnclosureSoil Interaction," Proc. SPIE 7017, Modeling, Systems Engineering, and Project Management for Astronomy III, 70171Y (11 July 2008); doi: $10.1117 / 12.792288$

Event: SPIE Astronomical Telescopes + Instrumentation, 2008, Marseille, France 


\title{
Finite Element Analysis of TMT Vibrations Transmitted through Telescope-Enclosure-Soil Interaction
}

\author{
Genady Shagal*a $^{\mathrm{a}}$, Doug G. MacMynowski ${ }^{\mathrm{b}}$, Konstantinos Vogiatzis ${ }^{\mathrm{c}}$ \\ ${ }^{a}$ Association of Canadian Universities for Research in Astronomy (ACURA)/Dept. of Astronomy \\ and Astrophysics, Univ. of Toronto, 50 St. George St., Toronto, Ontario, Canada, M5S 3H4; \\ ${ }^{\mathrm{b}}$ California Institute of Technology, Department of Control and Dynamical Systems, \\ Pasadena CA 91125 \\ ${ }^{\mathrm{c}}$ Thirty Meter Telescope Observatory, Pasadena, CA 91125
}

\begin{abstract}
Telescope-Enclosure-Soil Interaction could result in additional telescope movement due to two main sources: (i) enclosure windshake and (ii) vibrations of machinery located at enclosure, summit and utility facilities. To analyze and minimize these vibrations, a novel FE model was developed based on existing FE models for the TMT enclosure and telescope structures. This integrated structural model adequately represents propagation of vibrations from the source to the telescope structure through surrounding soil/rock region. The model employs 3-D linear-elastic harmonic analysis using commercial FE code ANSYS. Special attention was devoted to adequate modeling of reflecting and non-reflecting boundary conditions. Based on the FE model developed, we examined the effects of soil/rock stiffness and damping upon telescope vibrations and, ultimately, seeing quality. The effects of location, intensity and spectral content of main sources of machinery vibrations were also investigated.
\end{abstract}

Keywords: Thirty Meter Telescope (TMT), finite element analysis, vibration propagation

\section{INTRODUCTION}

To achieve expected image quality of Thirty Meter Telescope (TMT) all possible sources of image degradation should be carefully examined. Telescope vibrations are one of the major sources of degradation of image quality. While effect of wind induced forces acting on telescope structure was examined at the design stage for most modern large telescopes, the vibrations transmitted to telescope through surrounding soil/rock were never modeled. The large size of TMT results in (i) tight accommodation at the Armazones summit selected as reference site, and (ii) small relative distances between telescope pier, enclosure base, and summit and utility buildings. Therefore, vibrations caused by two sources: (i) enclosure windshake, and (ii) machinery vibrations (chiller plants, rotating fans, etc.) could propagate through soil to telescope pier and further to mirrors and instruments.

The existing telescope and enclosure models usually account for the effect of surrounding soil/rock as an infinite 3-D media $^{1}$ or as "equivalent" soil springs ${ }^{2}$. This approach is adequate for analysis of modal frequencies, displacements and stresses of telescope and enclosure as separate structures. However, it cannot be used to model interaction between these structures required to describe propagation of vibration from one structure to another through soil. Therefore, a coupled Telescope-Enclosure-Soil Finite Element model was developed to examine the two types of vibrations named above. Although this model is novel in the telescope design, transmission of vibrations through soil is widely modeled in analysis of vibrations caused by ground and underground trains $\mathrm{s}^{3,4}$. Similar analysis was also conducted for machinery vibrations in industrial buildings ${ }^{5,6}$ and for some scientific projects ${ }^{7,8}$.

*genady.sagals@utoronto.ca; phone 1905 761-2025; fax 1905 761-2025

Modeling, Systems Engineering, and Project Management for Astronomy III, edited by George Z. Angeli, Martin J. Cullum, Proc. of SPIE Vol. 7017, 70171Y, (2008) · 0277-786X/08/\$18 · doi: 10.1117/12.792288 
The objectives of this study were as follows:

- Analyze coupled enclosure-telescope-soil vibrations due to windshake and machinery vibrations

- Calculate movement of telescope and pintle bearing piers

- Analyze the effect of intensity and location of main sources of machinery vibrations

- Estimate the effect of soil and structural damping, and

- Analyze the effect of TMT site selection

This paper is divided into 6 sections. Following this introduction, Section 2 describes the finite element model used. In Section 3, we describe the vibration sources considered. In Section 4 we validate the finite element model. Section 5 discusses FE predictions and the effect of the pertinent parameters upon the vibrations of the telescope pier. Finally, in Section 6, we conclude the work.

\section{COUPLED FINITE ELEMENT MODEL}

\subsection{Layout of the selected FE model}

Fig. 1 shows expected TMT layout at the Armazones summit together with two vibration sources: enclosure windshake and machinery vibrations. Fig. 1 shows also vibration propagation path (red for wind induced and blue for machinery induced vibrations). The entire Finite Element model shown in Fig. 2 consists of five main components as follows:

- Enclosure FE model created by Dynamic Structures Ltd. (DSL) in Vancouver, Canada

- Drawings of the fixed base of the Enclosure created by M3 Engineering in Tucson, USA

- Telescope FE model created by DSL

- Drawings of the Telescope pier and pintle bearing support created by M3 Engineering

- Topography of Armazones summit created by M3 Engineering

The following assumptions were made:

- All components, including soil, are modeled as linear-elastic

- Full contact is assumed between all components

- Telescope and enclosure structures are assumed rigid at the current stage

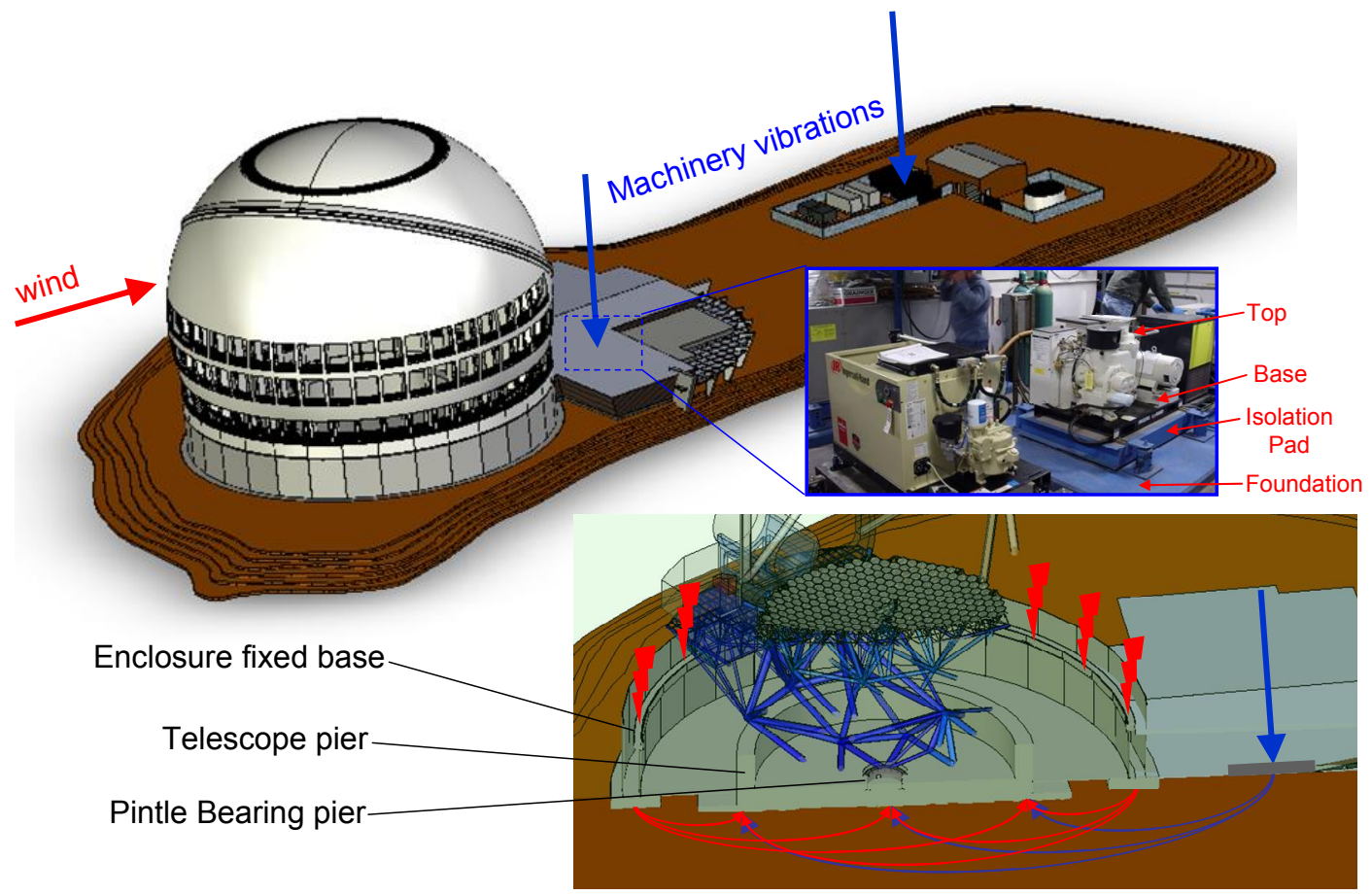

Fig. 1. TMT layout showing main sources of vibrations transmitted through soil/rock. 


\subsection{FE discretization}

FE model was created using commercial code ANSYS version 11. The same FE model was developed for both enclosure windshake and machinery vibrations. At the current stage, simplified FE model of assumed rigid enclosure was used. The resulting wind forces and moments applied to enclosure center of gravity (CG) were transferred to enclosure base through azimuth bearings modeled as springs. Rigid body constrains were used to transmit forces and moments through rigid enclosure. Rigid enclosure model was deemed appropriate, since the frequency range of windshake induced vibrations is well below the lowest enclosure frequency.

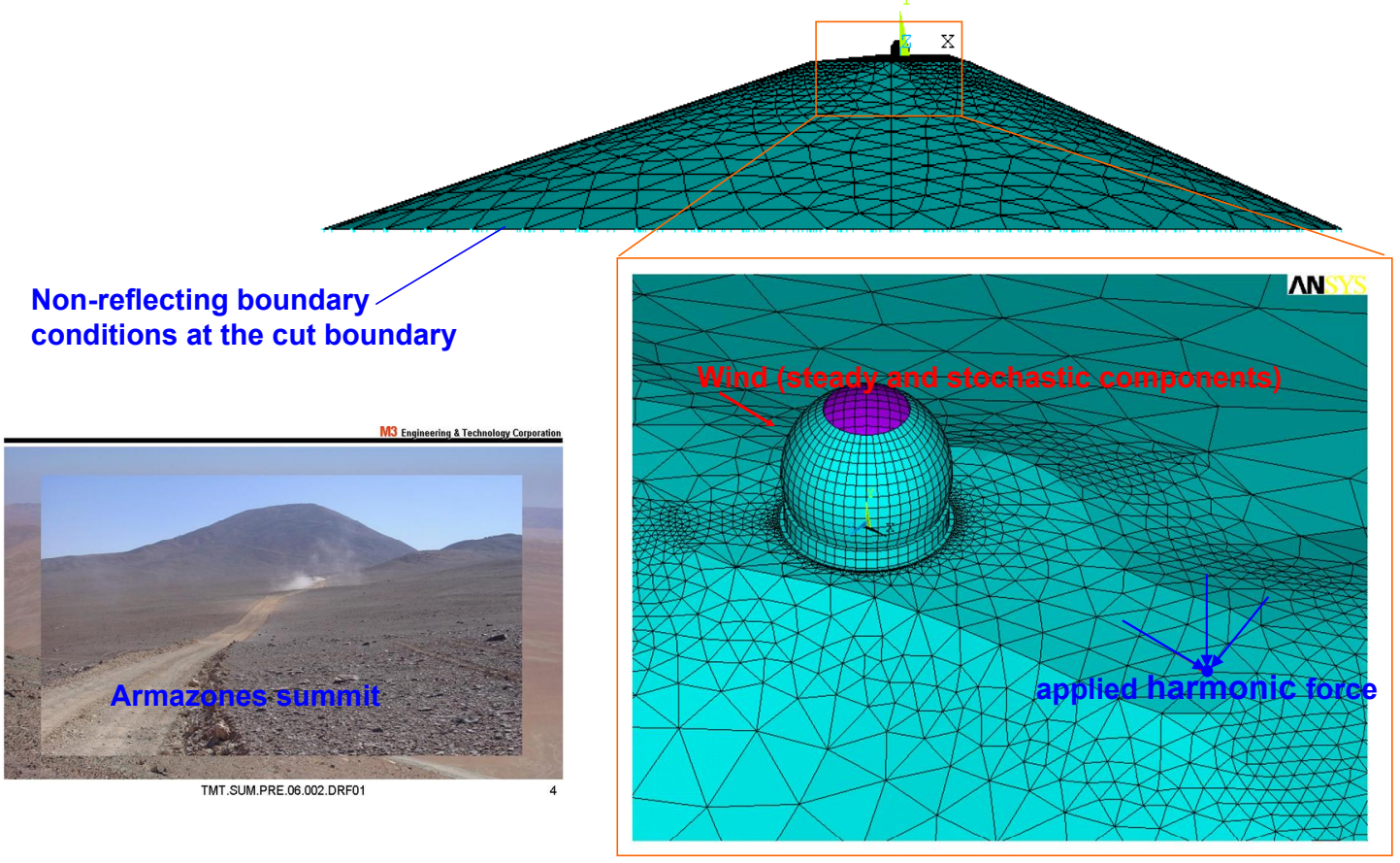

Fig. 2. FE model of TMT at Armazones summit.

Fig. 3 shows simplified FE model of assumed rigid telescope sitting on telescope and pintle bearing piers. Please notice, that hydrostatic telescope bearings, modeled as springs, transfer only vertical forces between telescope and pier. Horizontal loadings were transferred through pintle bearings, modeled also as springs. This simplified model of the telescope structure was used, since our objective was to model vibration propagation only to the telescope pier. Further propagation of vibrations through telescope structure involves modeling not only structural behavior but also control. All major commercial codes including ANSYS does not have the capability of modeling real control system. Therefore, a separate integrated FE model was created to analyze the propagation of telescope vibrations from the pier through the telescope structure and calculation of image motion?

Fig. 4 shows cross-section of the TMT with surrounding soil region. Two types of soil with different properties were selected in the current FE model: undisturbed soil and backfill soil. Free mesh consisting of eight-noded brick FE and four-noded tetrahedron FE was used to discretize enclosure and pier foundations and summit soil/rock. Fig. 4 shows also isometric view of the FE mesh selected. Practically, the 2-D FE model for cross-section X-Y was created first. This 2-D model was extruded into full $360^{\circ} 3$-D model by rotation around vertical y-axis. Please notice, that different mesh density was selected for TMT and soil in circumferential direction. This approach resulted in significant reduction of number of FE required and better shapes of these FE. Special procedure available in ANSYS was employed to "tie" components with different mesh densities and non-coincident nodes. 


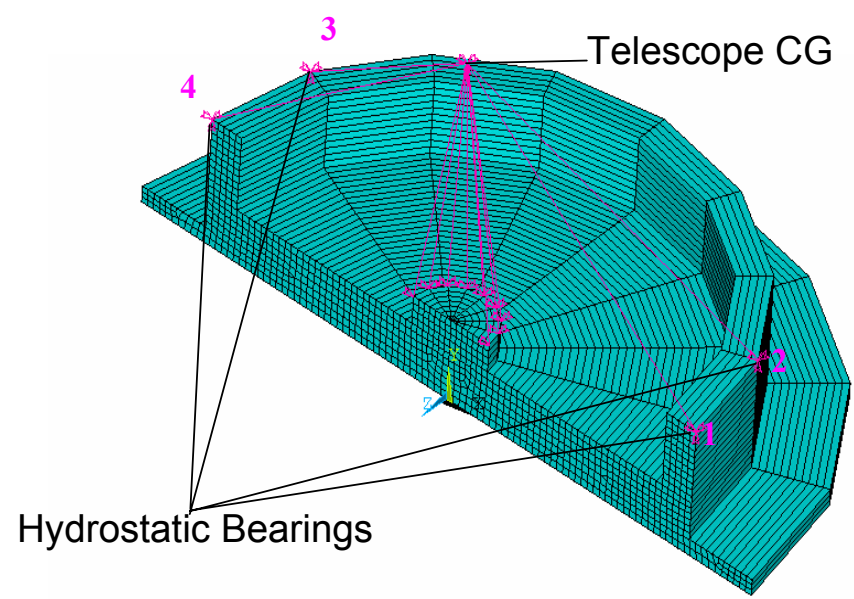

Fig. 3. FE model of TMT telescope and pier. Numbers show hydrostatic bearings locations.

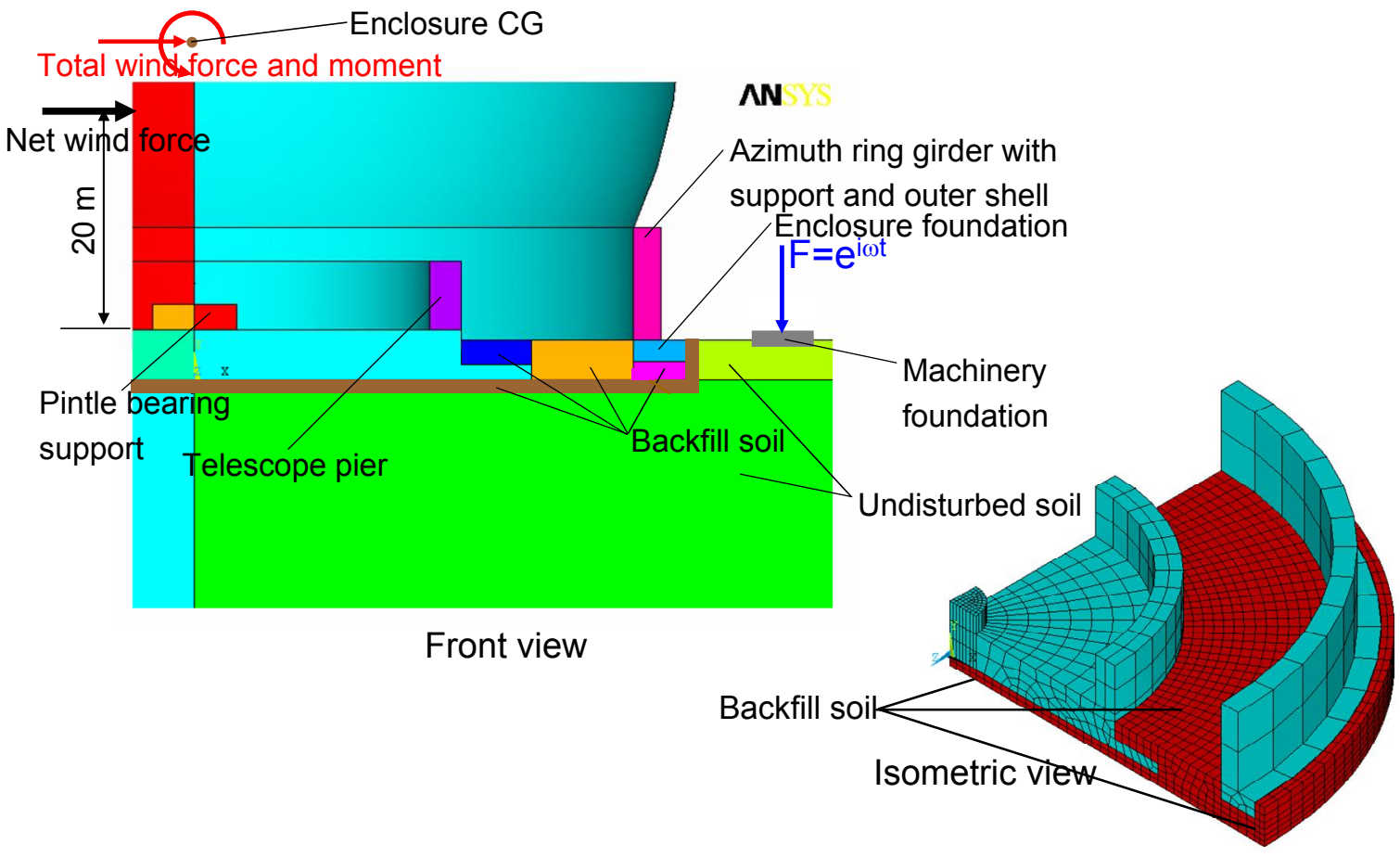

Fig. 4 TMT cross-section with surrounding soil/rock region.

\subsection{Modeling of infinite region}

Instead of modeling of practically infinite region of the entire Armazones mountain, non-reflecting cut boundary was introduced at the bottom of the selected mountaintop volume as shown in Fig. 2. This boundary was defined using widely used approach first proposed by Lysmer and Kuhlemeyer ${ }^{10}$. In this approach, specially selected viscous dampers were connected to all nodes of the cut boundary to prevent reflection of the vibration waves. Subsequently, this idea of lumped dampers has been used by other researchers (e.g. Dungar and Eldred ${ }^{11}$ ). As stated by Chow ${ }^{12}$, the viscous damper boundary is exact for one-dimensional problems. The correct dynamic viscous stress boundary condition, which must be applied to simulate the effect of damping for the one-dimensional propagation of compression wave is given by equation

$$
\sigma=\rho \cdot V_{p} \cdot \dot{u}
$$


where $\rho$ is the density of material, $V_{p}$, the velocity of compression wave and $\dot{u}$ the velocity of particles at boundary. In two-dimensional problems, the damper boundary is approximate. Following Lysmer and Kuhlemeyer ${ }^{10}$ the viscous stress condition may be written as

$$
\{\sigma\}=[D] \cdot\{\dot{u}\} \quad[D]=\rho \cdot\left[\begin{array}{cc}
a \cdot V_{p} & 0 \\
0 & b \cdot V_{s}
\end{array}\right],
$$

where $V_{s}$, is the velocity of shear wave and $a, b$ are dimensionless coefficients.

Based on a trial and error process, Lysmer and Kuhlemeyer found that very good absorption characteristics can be achieved with $a=b=1.0$ and this boundary has been termed a "standard viscous boundary". Three-dimensional case could be treated similar to two-dimensional case with one compressive and two shear waves.

\section{LOADINGS}

As was stated in introduction, we will consider two sources of vibrations transmitted to telescope through soil: enclosure windshake and machinery vibrations.

\subsection{Enclosure windshake}

These vibrations are produced by un-steady wind pressure acting on enclosure exterior shell. The resulting un-steady wind forces for TMT were calculated by MacMynowsky et al. ${ }^{9}$ and used as input in the current FE model as described below in section 5.1. As stated in this paper, at a $10 \mathrm{~m} / \mathrm{s}$ external wind, the unsteady wind forces on the TMT enclosure are roughly $10 \mathrm{kN}$ in the wind direction and $25 \mathrm{kN}$ in the orthogonal direction. The moments are accurately captured if the unsteady wind force is applied $20 \mathrm{~m}$ above the ground.

\subsection{Machinery vibrations}

Unfortunately, the exact types of equipment that will be used for TMT, their intensity and spectral contents are not clear yet. Therefore, unit harmonic forces or displacements were applied at possible locations to calculate transfer functions (TF) from vibrating machinery to telescope pier. Expected measurements for similar machinery at Keck will probably provide some specific information about these vibrations. However, TF allow conduct relative analysis of effect of TMT site selection, equipment location, etc. Such analysis is extremely important in the early design stage. Moreover, machinery vibrations were estimated based on existing LIGO data ${ }^{8}$, as described below in section 5.2.

\section{VALIDATION OF FE MODEL}

As stated in Introduction, coupled telescope-enclosure-soil model was never used for telescope design. Therefore, careful validation was conducted for the key new features of this model. First, FE predictions were compared with existing analytical and boundary element method solutions for the test case shown in Fig. 5 (Kokkinos and Spyrakos ${ }^{13}$ ). In this test the infinitely long rigid strip foundation, having width $2 b=5 \mathrm{ft}$, mass density $\rho_{f}=16.02 \mathrm{lb} \mathrm{sec} * / \mathrm{ft}$ and thickness $a=$ $0.5 \mathrm{ft}$ was placed on a linear elastic soil with elastic constants $E_{s}=2.58384 \times 10^{9} \mathrm{lb} / \mathrm{ft}^{2}, v_{\mathrm{s}}=0.25$ and mass density $\rho_{\mathrm{s}}=$ $10.68 \mathrm{lb} \mathrm{sec}^{2} / \mathrm{ft}^{4}$. The vertical and horizontal displacement amplitudes at the midpoint $\mathrm{C}$ of the strip were obtained for the loading cases shown in Fig. 5. Vertical and horizontal harmonic loads were applied in cases 1 and 2 respectively.

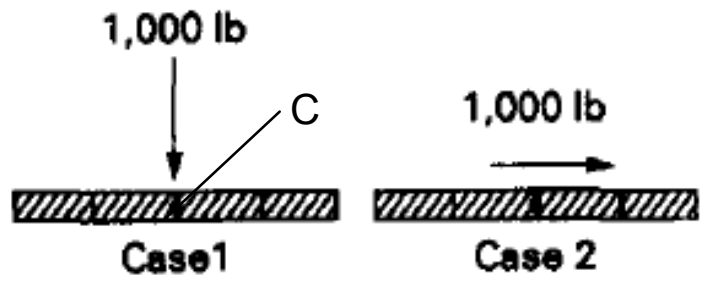

Fig. 5. Test cases for comparing current FE solution with the analytical/numerical solution ${ }^{13}$. 
Fig. 6 shows FE model developed for these two test cases. Dashpots were employed along the bottom and side lines of the model with damping coefficients calculated according to Eqn. (2). Plane strain 2-D state was selected to represent infinitely long rigid strips. Full harmonic analysis without additional material damping was conducted using commercial FE software ANSYS.

First, the results obtained using 4-noded and 8-noded 2-D solid FE were compared for the identical mesh. The comparison shows very similar results for these two cases for the mesh with reasonable density. Therefore, 4-noded FE with linear shape functions were selected for the further analysis due to much lower computational time. Fig. 7 shows the effect of size of soil region upon the vertical ( $y_{c}$ for Case 1) and the horizontal ( $x_{c}$ for Case 2) displacements of the strip centre $\mathrm{C}$ for the selected dimensionless frequency range from 0.5 to 1.5 . This range corresponds to values provided by Kokkinos and Spyrakos ${ }^{13}$. Dimensionless frequency $\omega$ was selected as follows:

$$
\omega=2 \pi f \times b / c_{2} \quad,
$$

where $c_{2}$ is the velocity of the shear wave in soil and $f$ is the frequency of applied force. The results show clearly that for $h / b \geq 30$ the FE results are close to analytical solution. Additional analysis was conducted to select optimum mesh density. This mesh density is governed by the two parameters: mesh size $l e$ at the strip foundation and mesh size $l e_{1}$ at the soil boundary. The results show that the selected soil region with $\mathrm{h} / \mathrm{b}=30$ and mesh density $l e=b / 4, l e_{1}=l e \times 4$ provide good results with the minimum number of FE required. The selection of optimum mesh density is very important for the 3-D cases where the large FE model could require very long run times.

Similar to cut boundary, the procedure of "tying" two regions with dissimilar meshes was also validated for the TMT geometry shown in Figs. 2 - 4. Further static and harmonic analyses conducted using different FE types and mesh densities show that the selected FE model with linear shape functions and mesh density shown in Figs. 2 - 4 provides adequate accuracy while keeping reasonable modeling time.

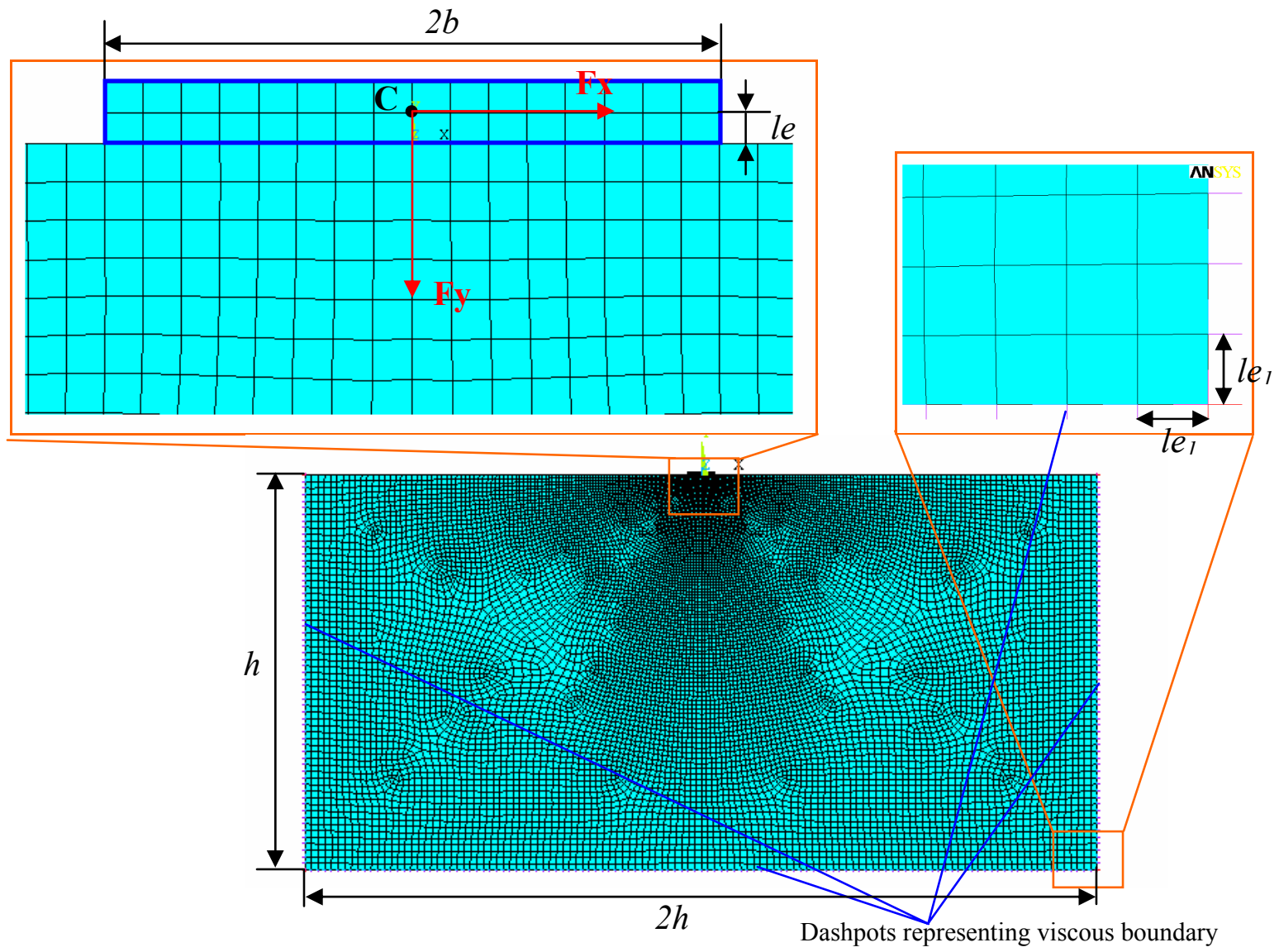

Fig. 6. FE model selected for comparison with paper ${ }^{13}$. 

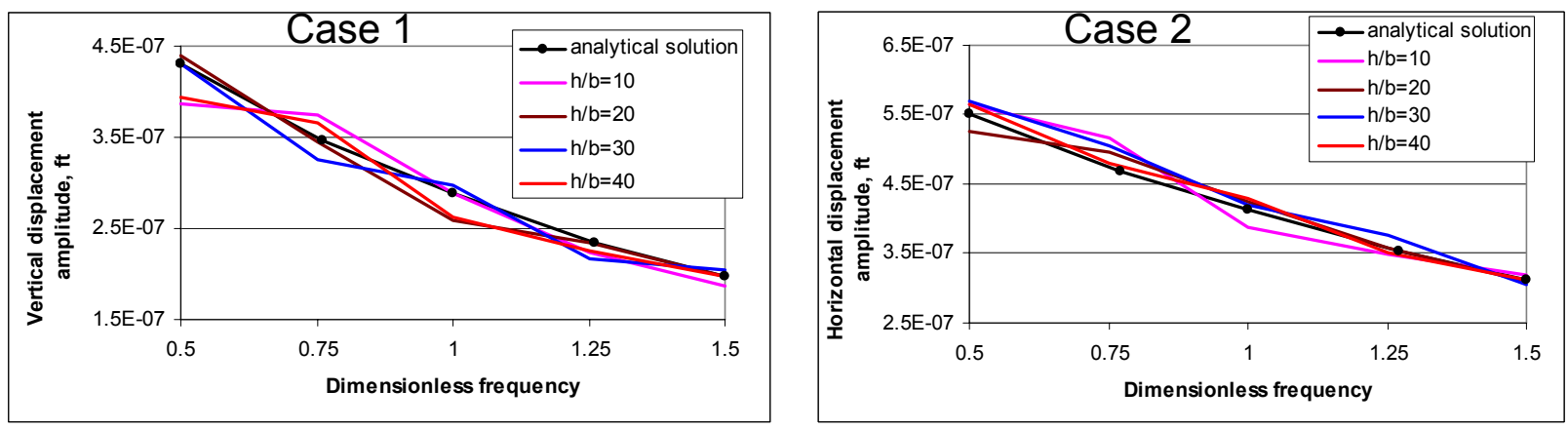

Fig. 7. Comparison between FE and analytical solutions for vertical $\left(\mathrm{y}_{\mathrm{c}}\right)$ and horizontal $\left(\mathrm{x}_{\mathrm{c}}\right)$ displacements of the strip centre for different sizes of soil region.

Table 1. Material properties and range of parameters examined.

\begin{tabular}{|c|c|}
\hline Description & Value \\
\hline Elastic modulus for undisturbed soil & $\begin{array}{c}124 \mathrm{MPa} \text { (soft soil of Mauna Kea) } \\
1200 \mathrm{MPa} \text { (stiff soil of Armazones) } \\
2900 \mathrm{MPa} \text { (stiff soil of Cerro Pachon) }\end{array}$ \\
\hline Elastic modulus for backfill soil & $\begin{array}{l}\text { Identical to the undisturbed soil, } \\
5 \text { times less, } 25 \text { times less }\end{array}$ \\
\hline $\begin{array}{l}\text { Elastic modulus for enclosure base and } \\
\text { telescope pier }\end{array}$ & $\begin{array}{l}24800 \mathrm{MPa} \text { (concrete) } \\
\text { Infinity (rigid parts) }\end{array}$ \\
\hline Poisson's ratio for soil & $\begin{array}{c}0.3 \text { (soft soil of Mauna Kea) } \\
0.18 \text { (stiff soil of Cerro Pachon \& Armazones) }\end{array}$ \\
\hline Soil damping ratio & 0,2 and $5 \%$ \\
\hline Poisson's ratio for concrete & 0.2 \\
\hline Soil density & $2000 \mathrm{~kg} / \mathrm{m} 3$ \\
\hline Concrete density & $2400 \mathrm{~kg} / \mathrm{m} 3$ \\
\hline Telescope mass & $1403 \mathrm{~T}$ \\
\hline Enclosure mass & $1506 \mathrm{~T}$ \\
\hline
\end{tabular}

\section{RESULTS AND DISCUSSIONS}

Quasi-static and harmonic FEA were conducted using material and geometry properties shown in Table 1. Armazones summit and $2 \%$ soil damping were selected as baseline case. Please notice, that TMT is currently in the preliminary design stage. Therefore, only limited number of results is presented in the current paper.

All FE predictions are grouped into two sections as described below. Please notice, that all results obtained so far are only preliminary estimations. Current FE model contains some material properties and assumptions that could not be validated numerically, such as soil properties, interfaces between soil and TMT components, etc. In the future, the FE model will be validated and calibrated based on planned vibration measurements at Keck.

\subsection{Results related to enclosure windshake}

Figs. 8 and 9 show the FE predictions related to transmission of enclosure windshake to telescope pier. Two nodes on opposite sides of the pier corresponding to two hydrostatic bearing locations were selected for output. Unit wind force 
was applied to the enclosure at the location corresponding to net wind force ( $20 \mathrm{~m}$ above the ground level). Therefore, the calculated pier displacements are actually transfer functions (TF) from enclosure to pier. These TF are complex values. In the current paper we used only TF amplitudes for analysis of different cases examined. However, both real and imaginary values of pier vibrations were used in subsequent analysis of telescope structure. Please notice, that FE model with non-reflecting cut boundary is not sufficiently constrained in quasi-static solution corresponding to zero frequency in harmonic analysis. Therefore, additional constrains at the bottom of the FE model were applied to ensure convergence of quasi-static solution. Fig. 8 shows the effect of wind direction for the Armazones location. Fig. 9 shows the effect of site selection (Armazones versus Mauna Kea). The frequency range from zero to $10 \mathrm{~Hz}$ was selected for harmonic analysis. This range is more than adequate to cover all frequencies with significant wind energy. Fig. 10 shows Power Spectral Density (PSD) of un-steady wind forces acting on enclosure exterior shell ${ }^{9}$ as described in section 3.1. The wind spectrum used is for a $10 \mathrm{~m} / \mathrm{s}$ external wind. This PSD was used as input for calculation of pier displacements using TF obtained in the current paper.

The predicted pier displacements were applied to the TMT integrated model developed by MacMynowsky et al. ${ }^{9}$ that includes the telescope dynamics, relevant control loops (mount control and guide loops in particular) and a linear optical model in order to obtain PSD, root mean square (RMS) and maximum values of image motion. Fig. 11 shows predicted image motion in mas for Armazones site. The lower plot in Fig. 11 is the PSD of the optical Line of Sight (LOS) resulting from wind, and the upper plot is the cumulative values. As evidenced, the total response is just under 1 mas image motion. The plots in Fig. 11 are for both telescope upwind and $90^{\circ}$ orientations. Based on obtained values of TF, image motion for Mauna Kea site should be a factor of 9-10 or so higher due to the higher soil transmissibility. (The calculation includes wind spectrum, from both along-wind and transverse directions.

Please notice, that at that wind speed $(10 \mathrm{~m} / \mathrm{s})$, the image motion due to forces on the telescope itself is about 19 mas $^{9}$.

\subsection{Results related to machinery vibrations}

Two different locations of vibrating machinery were selected for analysis as shown in Fig. 12.

Figs. 13 shows TF for total amplitudes of pier displacements caused by unit harmonic force applied at the utility building for absolutely rigid and concrete pier respectively. Extended frequency range from 0 to $50 \mathrm{~Hz}$ was selected to cover all expected dominant frequencies caused by machinery. Since the dominant direction of applied vibrations is not yet determined, all three directions: vertical along $\mathrm{y}$-axis and two horizontal along $\mathrm{x}$ - and $\mathrm{z}$ - axis were examined. FE predictions in Fig. 13 show approximately the same level of TF in all three directions selected. Fig. 13 also shows significant effect of pier stiffness for frequencies more than $15 \mathrm{~Hz}$. Finite pier stiffness leads to significant decrease in TF for higher frequencies. Therefore, TF should be recalculated at the time the final design of the pier will be selected.

Fig. 14 shows the effect of site selection upon total amplitudes of pier vibrations. Total values for TF of pier vibrations were calculated by adding in quadrature all three components along x-, y- and z-axes. Similar to Fig. 13, vibrations caused by unit applied force in all three directions were examined. The results in Fig. 14 clearly show significantly lower level of pier vibrations for Mauna Kea site for high frequencies $(>20 \mathrm{~Hz})$ due to lower values of assumed soil stiffness (124 MPa for Mauna Kea versus $1200 \mathrm{MPa}$ for Armazones).
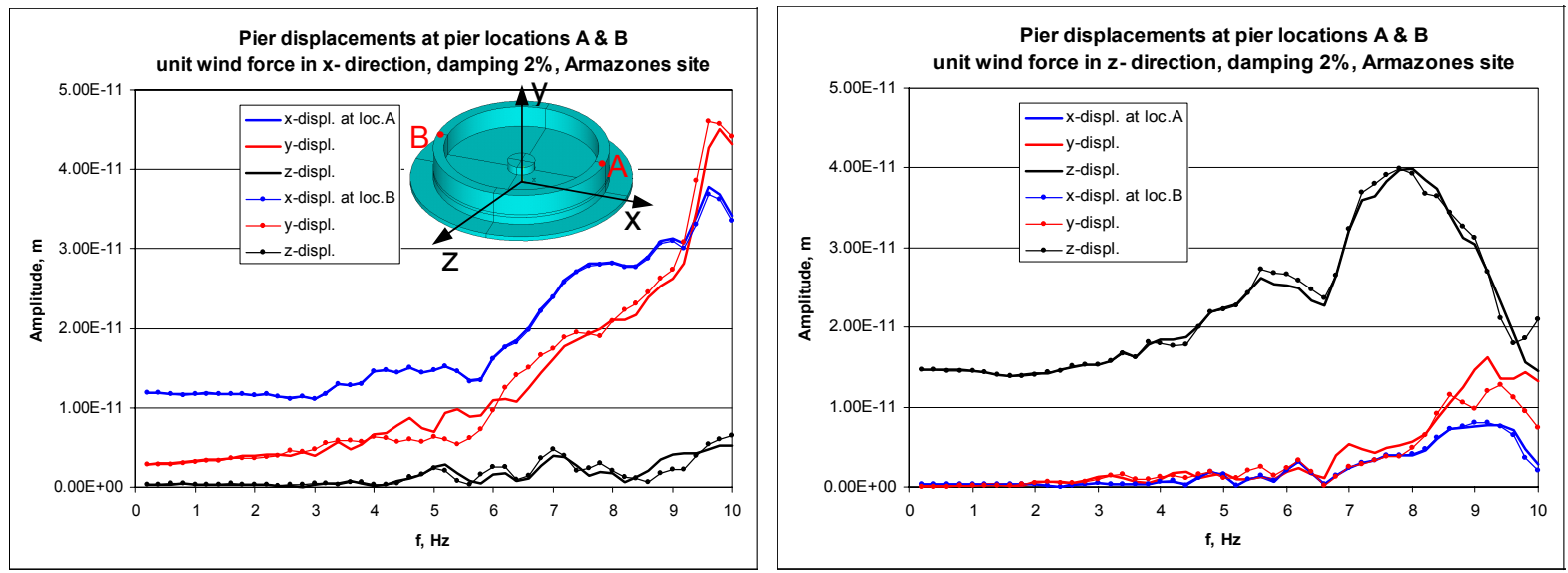

Fig. 8. TF for total amplitude of pier displacement due to windshake (baseline case) 

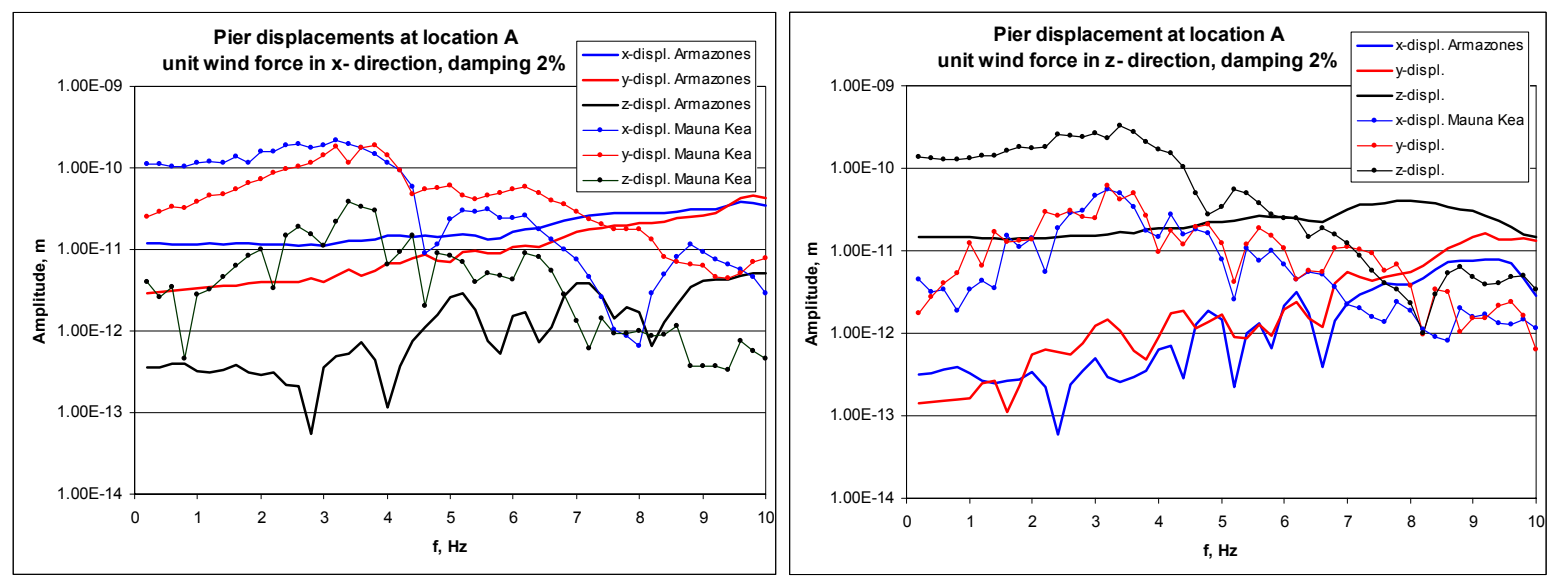

Fig. 9. Effect of site selection (Armazones versus Mauna Kea) upon pier TF due to windshake

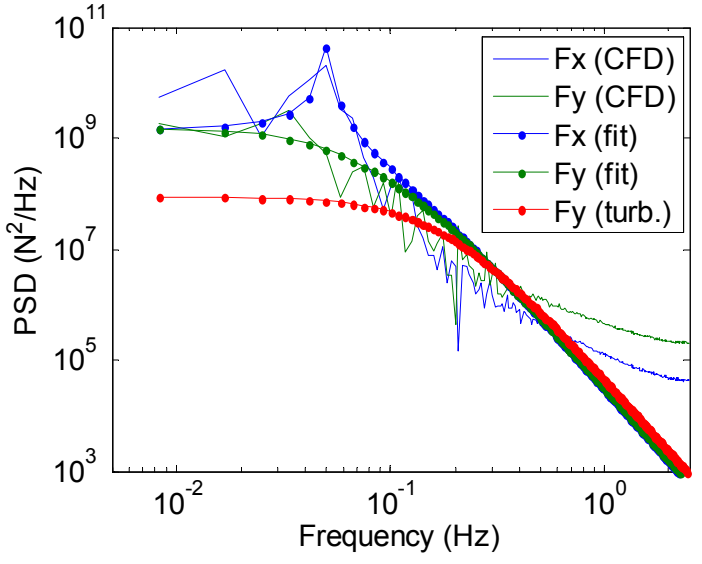

Fig. 10. PSD of un-steady wind forces acting on enclosure exterior shell ${ }^{9}$
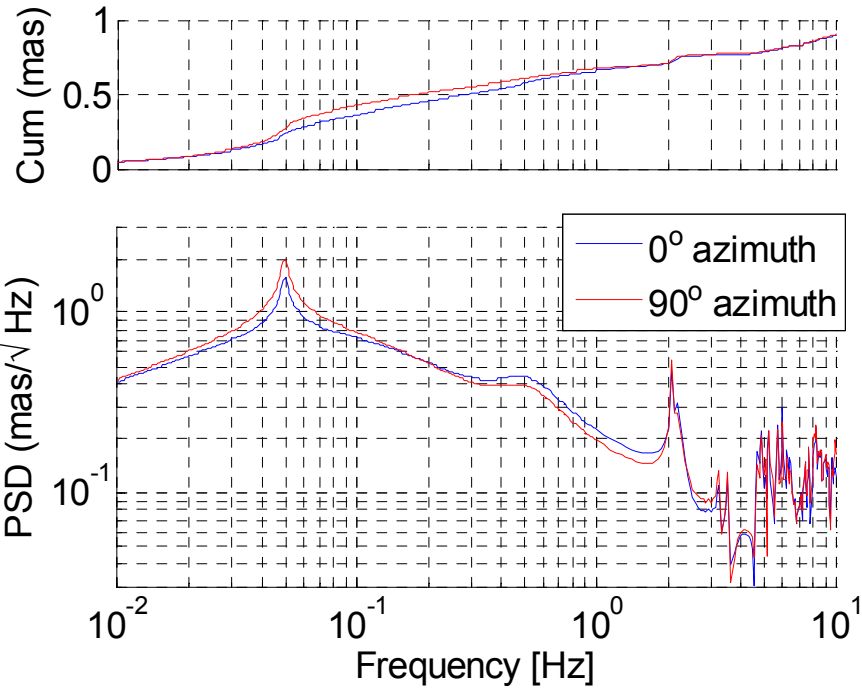

Fig. 11. Predicted image motion for Armazones site due to windshake ${ }^{9}$

The exact type of machinery for the TMT, their locations on the summit and suspensions are not selected yet. However, we decided to do some preliminary estimation of the level of these vibrations based on existing data for similar equipment ${ }^{8}$. According to these data, rotating fans and chiller plant are the two major sources of vibrations as follows:

Four air handling fans with $750 \mathrm{lb}$ rotors operating at corner station with unbalanced vibrations of $0.1 \mathrm{~g}$ produce vibrations in range from 29 to $31 \mathrm{~Hz}(1800 \mathrm{rpm})$. Imbalance of $10 \%$, assuming there is no reason for the imbalances to be in phase, so adding in quadrature, gives $\sim 300 \mathrm{lb}$ total imbalance force. Further more, a factor of 6 for fan frequency above the isolator frequency means $\sim$ factor of 36 reduction, or $\sim 4.2 \mathrm{lb}$ at base of isolator, hence about $20 \mathrm{~N}$.

Chiller equipment rotates at $60 \mathrm{~Hz}(3600 \mathrm{rpm})$ and weighs $21,400 \mathrm{lbs}$, mounted on a spring isolated skid. Similar to fans, $10 \%$ imbalance for chiller plant and an isolation frequency of $6 \mathrm{~Hz}$ ( $\sim$ factor of 100 reduction) lead to $\sim 21.4 \mathrm{lb}=100 \mathrm{~N}$ force at base of isolator.

Please notice, that the $10 \%$ imbalance is quite a severe case; it could be at least a factor of a few better. However, these conservative values were used for estimation of pier displacements as shown in Tables 2 and 3. Maximum values of TF over the frequency ranges $28-32 \mathrm{~Hz}$ for fans and $58-62 \mathrm{~Hz}$ for chiller plant were selected in Tables 2 and 3 respectively. 


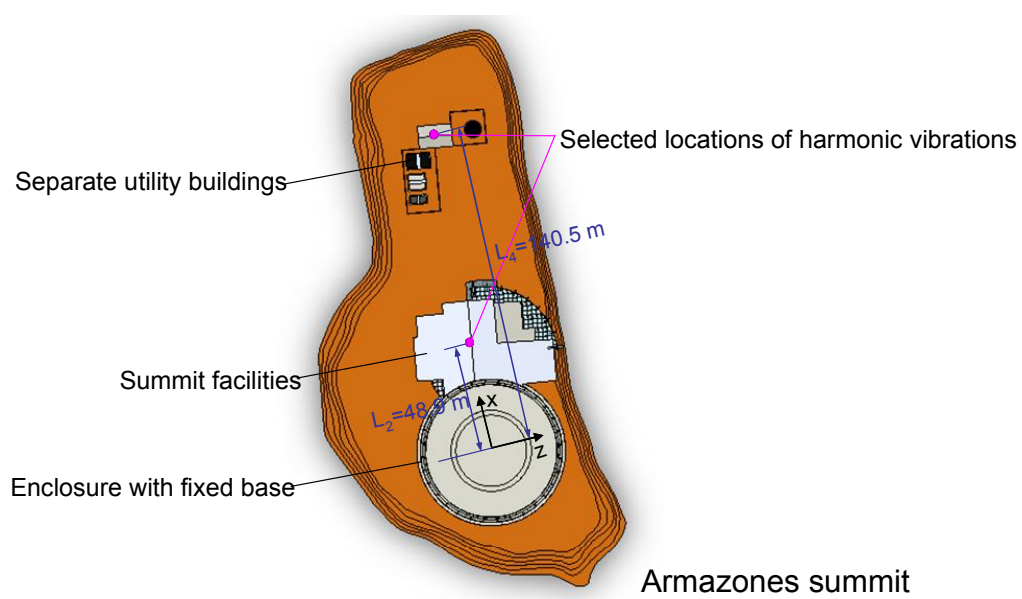

Fig. 12 Selection of expected locations of machinery vibrations at Armazones summit.

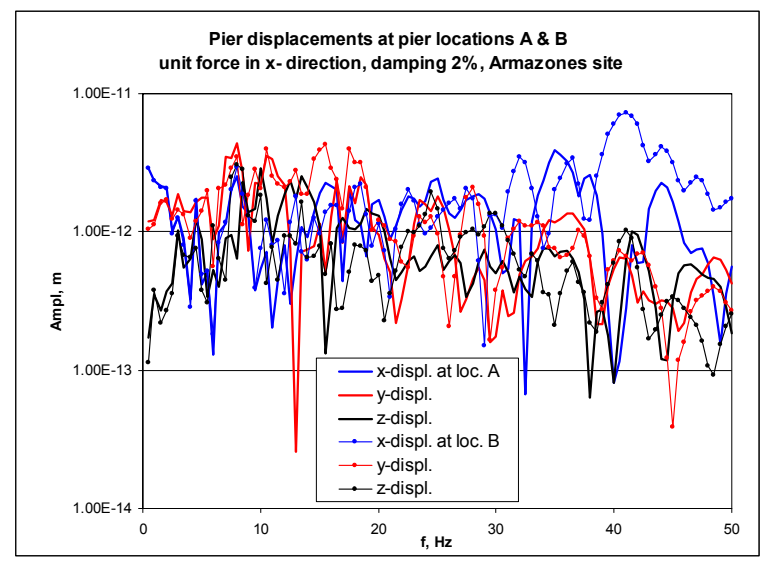

Concrete pier

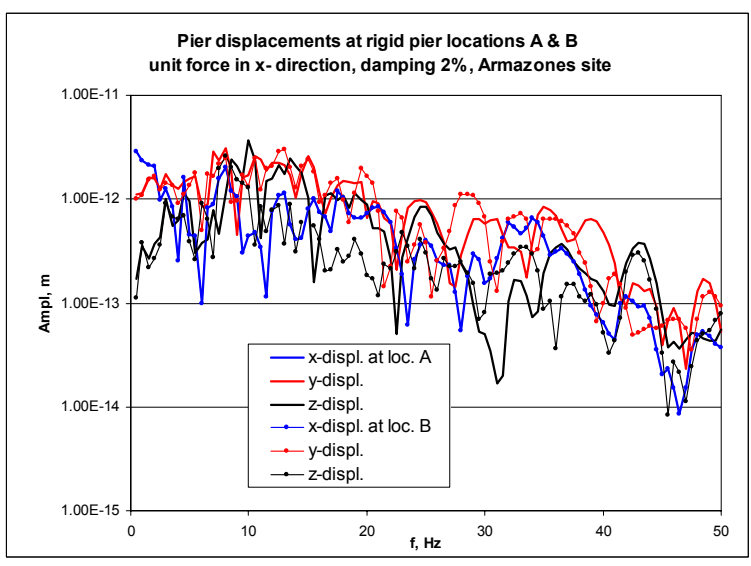

Absolutely rigid pier

Fig. 13. TF for amplitudes of pier displacement due to machinery vibrations at utility building.

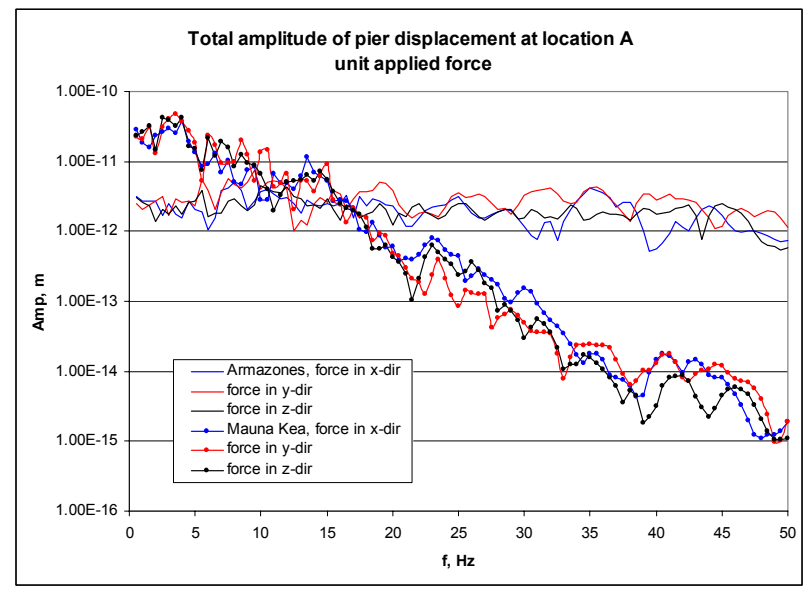

Fig. 14. Effect of site selection (Armazones versus Mauna Kea) upon total pier TF due to machinery vibrations at utility building. 
Table 2. Pier TF for applied unit force $(\mathrm{m} / \mathrm{N})$. Numbers in red are amplification factors for vibrations applied at summit facility relative to utility building

\begin{tabular}{|c|c|c|c|c|}
\hline \multirow{2}{*}{$\begin{array}{l}\text { Vibration } \\
\text { direction }\end{array}$} & \multicolumn{2}{|c|}{ Rotating fans $(29-31 \mathrm{~Hz})$} & Chiller plant $(60 \mathrm{~Hz})$ \\
\cline { 2 - 5 } & Summit facility & Utility building & Summit facility & Utility building \\
\hline $\mathrm{x}$ & $1.62 \mathrm{E}-11(\times 4.55)$ & $3.56 \mathrm{E}-12$ & $1.57 \mathrm{E}-11(\times 18.5)$ & $8.48 \mathrm{E}-13$ \\
\hline $\mathrm{y}$ & $9.13 \mathrm{E}-12(\times 1.93)$ & $4.74 \mathrm{E}-12$ & $7.94 \mathrm{E}-12(\times 2.60)$ & $3.05 \mathrm{E}-12$ \\
\hline $\mathrm{z}$ & $4.64 \mathrm{E}-12(\times 1.91)$ & $2.43 \mathrm{E}-12$ & $5.78 \mathrm{E}-12(\times 10.4)$ & $5.55 \mathrm{E}-13$ \\
\hline $\mathrm{5}$ & $1.88 \mathrm{E}-11(\times 109)$ & $1.73 \mathrm{E}-13$ & $1.24 \mathrm{E}-12(\times 337)$ & $3.68 \mathrm{E}-15$ \\
\hline $\mathrm{y}$ & $1.50 \mathrm{E}-11(\times 162)$ & $9.25 \mathrm{E}-14$ & $2.21 \mathrm{E}-12(\times 491)$ & $4.50 \mathrm{E}-15$ \\
\hline $\mathrm{z}$ & $1.35 \mathrm{E}-11(\times 99.3)$ & $1.36 \mathrm{E}-13$ & $2.29 \mathrm{E}-12(\times 923)$ & $2.48 \mathrm{E}-15$ \\
\hline
\end{tabular}

Table 3. Amplitude of pier displacements. Input machinery forces are as follows: $75 * 2 / 36 \mathrm{lbf}=20 \mathrm{~N}$ for $30 \mathrm{~Hz}$; $21400 * 10 \% / 100=21.4 \mathrm{lbf}=100 \mathrm{~N}$ for $60 \mathrm{~Hz}$

\begin{tabular}{|c|c|c|c|c|}
\hline \multirow{2}{*}{$\begin{array}{l}\text { Vibration } \\
\text { direction }\end{array}$} & \multicolumn{2}{|c|}{ Rotating fans $(29-31 \mathrm{~Hz}), \mathrm{nm}$} & \multicolumn{2}{c|}{ Chiller plant $(60 \mathrm{~Hz}), \mathrm{nm}$} \\
\cline { 2 - 5 } & Summit facility & Utility building & Summit facility & Utility building \\
\hline $\mathrm{x}$ & 0.324 & 0.0712 & 1.57 & 0.0848 \\
\hline $\mathrm{y}$ & 0.182 & 0.0948 & 0.794 & 0.305 \\
\hline $\mathrm{z}$ & 0.0928 & 0.0486 & 0.578 & 0.0555 \\
\hline $\mathrm{x}$ & 0.376 & 0.00346 & 0.124 & 0.000368 \\
\hline $\mathrm{y}$ & 0.3 & 0.00185 & 0.221 & 0.00045 \\
\hline $\mathrm{z}$ & 0.27 & 0.00272 & 0.229 & 0.000248 \\
\hline
\end{tabular}

\section{CONCLUSIONS}

A novel coupled Telescope-Enclosure-Soil FE model was developed and validated for TMT. This model is capable of modeling vibration propagation from vibration sources through the soil to the telescope pier. Two major sources of vibrations were considered: (i) enclosure windshake caused by un-steady wind pressure, and (ii) vibrations caused by rotating or moving machinery, such as chiller plants or fans. The FE predictions show insignificance of enclosure windshake for image motion. However, machinery vibrations could play a role in deteriorating of image quality and, therefore, should be carefully examined at later design stage using proposed FE model. Please notice, that all results obtained so far are only preliminary estimations. Further validation and calibration of FE model will be conducted based on planned vibration measurements at Keck. The intention of TMT team is to use the proposed FE model as an instrument for selection of optimum machinery types and locations at early design stage.

\section{ACKNOWLEDGEMENTS}

The TMT Project gratefully acknowledges the support of the TMT partner institutions. They are the Association of Canadian Universities for Research in Astronomy (ACURA), the California Institute of Technology and the University of California. This work was supported as well by the Gordon and Betty Moore Foundation, the Canada Foundation for Innovation, the Ontario Ministry of Research and Innovation, the National Research Council of Canada, the Natural Sciences and Engineering Research Council of Canada, the British Columbia Knowledge Development Fund, the Association of Universities for Research in Astronomy (AURA) and the U.S. National Science Foundation.

\section{REFERENCES}

${ }^{[1]}$ OWL Concept Design Report. Phase A Design Review (OWL Blue Book). OWL TRE-ESO-0000-0001 Issue 2. http://www.eso.org/sci/facilities/eelt/owl/Blue_Book/OWL_Blue_Book_II.pdf. 
${ }^{[2]}$ Thirty Meter Telescope construction proposal. September 12 (2007) http://www.tmt.org/news/TMTConstruction\%20Proposal-Public.pdf.

[3] Hung, H., and Yang, Y., "A Review of Researches on Ground-Borne Vibrations with Emphasis on Those Induced by Trains," Proc. Natl. Sci. Counc. ROC(A), Vol. 25, No. 1, 1-16 (2001).

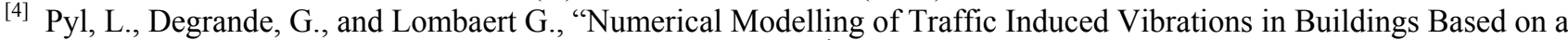
Dynamic Soil-Structure Interaction Formulation," Proc. $15^{\text {th }}$ ASCE Eng. Mech. Confer., June 2-5, Columbia Univ., New York, NY. (2002).

${ }^{[5]}$ Gazetas, G., "Analysis of Machine Foundation Vibrations: State of the Art," Soil Dynamics and Earthquake Eng., Vol. 2, No. 1, 2-42 (1983).

[6] Wolf, J. P., and Deeks A. J., [Foundation Vibration Analysis: A Strength-of-Materials Approach], Elsevier (2004).

[7] Asiri, F., Le Pimpec, F., and Seryi A., "Study of Near-Field Vibration Sources for the NLC LINAC Components," Stanford Linear Acceleration Center, Stanford University, Paper presented at the Particle Acceleration Conference (PAC 03), Portland, OR, May 12-16 (2003).

[8] Coyne, D., "LIGO - The Laser Interferometer Gravitational-wave Observatory. Vibration and Facility Considerations," Presentation at the TMT Vibration Workshop, Pasadena, CA, Oct. 16 (2007).

[9] MacMynowski, D. G., Blaurock C., and Angeli, G. Z., "Dynamic Analysis of TMT," Proc. SPIE, 7017-31 (2008).

${ }^{[10]}$ Lysmer, J.,and Kuhlemeyer, R.L., "Finite Dynamic Model for Infinite Media," J. Engineering. Mech. Div., ASCE, Vol. 95, No. 4, 859-877 (1969).

${ }^{[11]}$ Dungar, R., and Eldred, P., "The Dynamic Response of Gravity Platforms," Earthquake Eng. Struct. Dynamics, Vol. 6, 123-138 (1978).

${ }^{[12]}$ Chow, Y. K., "Accuracy of consistent and lumped viscous dampers in wave propagation problems," Int. J. for Num. Methods in Eng., Vol. 21, 723- 732 (1985).

${ }^{[13]}$ Kokkinos, F. T., and Spyrakos, C. C., "Dynamic Analysis of Flexible Strip-Foundations in the Frequency Domain," Computers \& Structures Vol. 39, No. 5, 473-482 (1991). 